\title{
EFFECTIVENESS ANALYSIS OF A THERMO-SIPHON CHARGED WITH NORFLURANE AS A RUNNING FLUID WITH ELECTRO CHEMICAL NANO COATING
}

\author{
Parthiban $\mathbf{M}^{1}$, Vivek $\mathrm{T}^{\mathbf{2}}$, Kanagaraj $\mathrm{K}^{\mathbf{3}}$ \\ ${ }^{1,2,3}$ PG Student, S.N.S College of Technology, Coimbatore, Tamilnadu, India.
}

\begin{abstract}
This work presents an investigation of the thermal performance on Thermo-siphon charged with norflurane as a running fluid, with electro chemical nano coating. This analysis was carried out to scrutinize the optimized fill ratio and angle of inclination for better heat transfer enhancement. The fluctuation of heat transfer ability of the thermo-siphon was analyzed for the input heat transfer rate varies from 0 to $350 \mathrm{~W}$ for various filling ratios and inclination of angle. The various fill ratio of the refrigerant used in the analysis are $70 \%, 60 \%, 50 \%, 40 \%$ and $30 \%$ and angle of inclination for carrying out orientation analysis were taken as $0^{\circ}$, $45^{\circ}$ and $90^{\circ}$. Experimental results showed that the fill ratio and orientation analysis showed a better heat transfer performance on thermo-siphon while using Norflurane as a working fluid. Experimental investigations and calculations depicted that the thermal resistance of $50 \%$ fill ratio was found to be lower than that of other fill ratios thereby leading to a better thermal performance for thermo-siphon charged with Norflurane. Further, upon further investigation for orientation analysis it was found that the horizontal inclination provided better heat transfer. Hence this present investigation indicates that the thermal performance of a thermo-siphon can be enhanced using Norflurane at an optimal fill ratio of $50 \%$ and at an angle of inclination of $0^{\circ}$.
\end{abstract}

Keywords: Angle of Inclination, Filling Ratio, Heat Transfer, Norflurane, Thermal Resistance,Thermo-Siphon, Electro Chemical Nano Coating.

\section{BASIC PRINCIPLE}

In Two-phase closed loop Thermo-siphon [1] is a very in complex and very efficient heat transfer device. It is superthermal conductor that transmits heat at small temperature difference by evaporation and condensation of the running fluid. Thus the running fluid which is a condensate stage comes back to evaporator due to the gravitational force and the temperature difference between both the ends. Thermosiphon is also known to be a passive device as heat is transferred within the tube by buoyancy force. It does not possess any moving parts and for its working it does need any external source to gear its process. Thus, it can be easily manufactured at low fabrication cost. Due to its lower thermal resistance, thermo-siphon transfers large amount of heat at small temperature differences. Heat transfer in thermo-siphon has been experimentally studied and verified by many researchers. For instance M. Kannan [2] analysed the operating parameters on the heat transfer ability of a 2phase thermo-siphon charged with different running fluids. He concluded upon his research work that thermo-siphon being a passive device transported heat effectively with low temperature differences. K. S. Ong [3] et al analyzed in their paper that the 2- phase closed thermo-siphon is found to be a good heat transfer device experimentally with varies inclinations [4] and heat input. They are generally demonstrate to be very effective, low cost and reliable heat transfer devices for applications in many thermal management and heat recovery systems. Figure.1 make clear that the typical 2-phase closed thermo-siphon which consists of a copper pipe with a known amount of running liquid fluid sealed inside. The vapour in the condenser zone is at a lesser pressure than in the evaporator section causing the vaporization to flow upward. In the cooler condenser [5] region the vapor distil thus releasing the latent heat that was absorbed in the evaporator section.

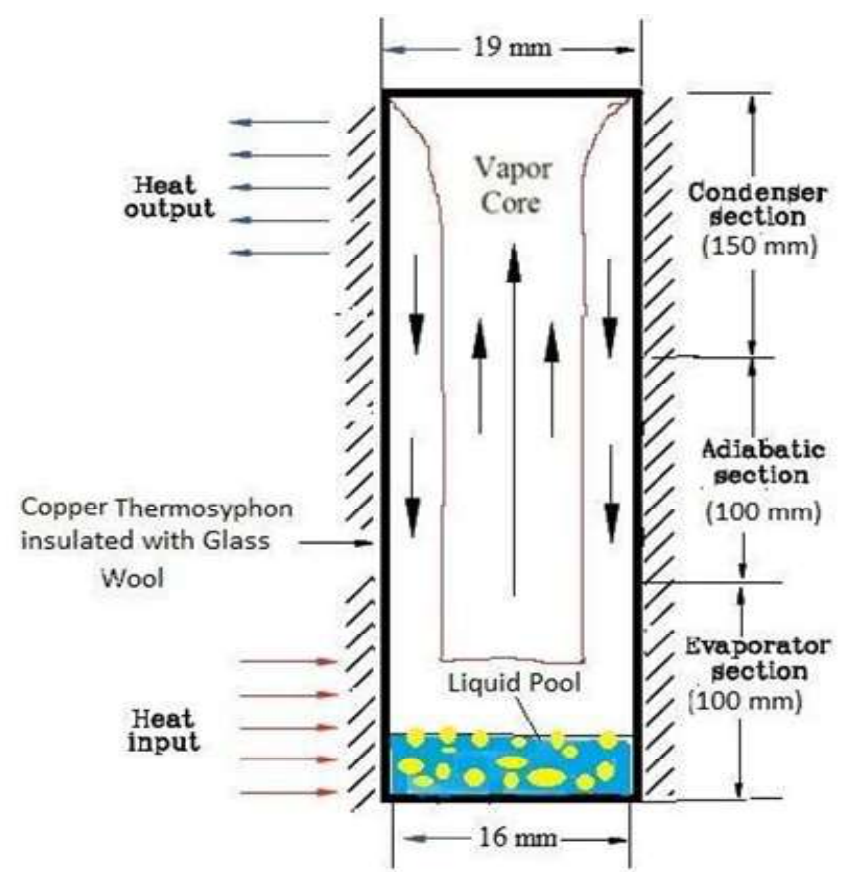

Fig 1. Schematic Diagram of a 2-Phase Thermo-siphon 
Thus the refrigerant at a vaporized state returns at the effect of temperature difference thereby leading to a density difference causing it condense and come back to the evaporator region.

\section{EXPERIMENTAL APPARATUS}

AND

\section{PROCEDURE}

\subsection{Working Fluid}

The working fluid is chemically termed chemically as $1,1,1,2-$ Tetraflouroethane is a halo alkane refrigerant. In lay terms it is called as Norflurane and its thermodynamic are similar to that of R-12 (dichlorodifluoromethane), but with lower global warming and ozone depletion potential. It is safer for normal handling as it is non-toxic, non-combustible and non-sarcastic working fluid.

Researcher Alberto Cavallini [6] in his paper discusses about the running fluids for refrigeration. In this, he discusses about choice and replacement of fluids with primary affair must be give to minimize the total global warming impact, which for most applications calls for improved energy efficiency. He also discusses the main issues associated with the use of the new generation refrigerants such as behavior with oil flammability efficient use of temperature glides, fractionation distillation and heattransfer degradation, the operating range of various refrigerants Norflurane and its properties (physical, chemical) are widely discussed in this research study.

Various researcher scholars have used Norflurane in their experimental thesis. K.S. Ong [7] et al concluded in their paper regarding the Thermal efficiency of 2- phase thermosiphon filled with Norflurane. The effects of temperature difference between bath and condenser section, fill ratio and coolant mass flow rates on the performance of the thermosiphon were ascertained. The experimental results indicate that while using Norflurane as a working fluid the heat flash transferred increased with increasing coolant mass flow rate, fill ratio and temperature discrepancy between bath and condenser section. M. H. M. Grooten [8] et al presented a paper and analyzed on the thermo-siphon filled with Norflurane with lot of parameters such as filling ratio and angle of inclination.

\subsection{EXPERIMENTAL SETUP}

The setup as shown below in Figure 2 consists of a test rig upon which has a two phase closed loop thermo-siphon is mounted. It is a Copper thermo-siphon. The measurements of the thermo-siphon were measured to be $350 \mathrm{~mm}$ long, $19 \mathrm{~mm} \mathrm{O} / \mathrm{D}$ and $16 \mathrm{~mm} \mathrm{I/D}$. The fluctuation of heat transfer ability of the thermo-siphon was studied for the input heat transfer rate ranging from 0 to $400 \mathrm{~W}$ for different filling ratios and with operating temperature from $30^{\circ} \mathrm{C}$ to $120^{\circ} \mathrm{C}$. The condenser is connected to tube which allows water from chilling unit to flow through the thermo-siphon. Using the software the measurement of evaporator, condenser and adiabatic sections of Temperature dispensation along the external surface will be measured. Thermocouples were connected to a data logger connected to a computing device; $350 \mathrm{~mm}$ long thermo-siphon consists of an insulated material such as glass wool which prevents heat from dissipating from the system. Coolant water, bath temperature was calibrated by using thermocouples. A bath in the chilling unit was aroused slowly to ensure no temperature stratification within the bath. Temperature departs between the top and bottom of the bath was less than $0.5^{\circ} \mathrm{C}$.

Table 1.1 Experimental Setup Descriptions

\begin{tabular}{|c|c|c|}
\hline \multicolumn{2}{|c|}{ Tube Material } & Copper \\
\hline \multirow{3}{*}{ Diamteter } & Internal & $16 \mathrm{~mm}$ \\
\cline { 2 - 3 } & External & $19 \mathrm{~mm}$ \\
\hline \multirow{3}{*}{ Dimensions } & Total & $350 \mathrm{~mm}$ \\
\cline { 2 - 3 } & Evaporator & $100 \mathrm{~mm}$ \\
\cline { 2 - 3 } & Condenser & $150 \mathrm{~mm}$ \\
\cline { 2 - 3 } & Adiabatic & $100 \mathrm{~mm}$ \\
\hline \multicolumn{2}{|c|}{ Filling Fluid } & Refrigerant $-\mathrm{R} 134 \mathrm{a}$ \\
\hline Angle of Inclination & $0^{\circ}, 45^{\circ}$, and $90^{\circ}$ \\
\hline \multicolumn{2}{|c|}{ Filling Ratio } & $70 \%, 60 \%, 50 \%, 40 \% 30 \%$ \\
\hline \multirow{2}{*}{ Thermocouple } & T Type $[$ Temp. Range- \\
& $270^{\circ} \mathrm{C}$ to $370^{\circ} \mathrm{C}$ \\
\hline \multicolumn{2}{|c|}{ Collant flow rate } & 24 Litre per hour \\
\hline \multicolumn{2}{|c|}{ Heat Input } & Variable $(0-350)$ Watts \\
\hline
\end{tabular}

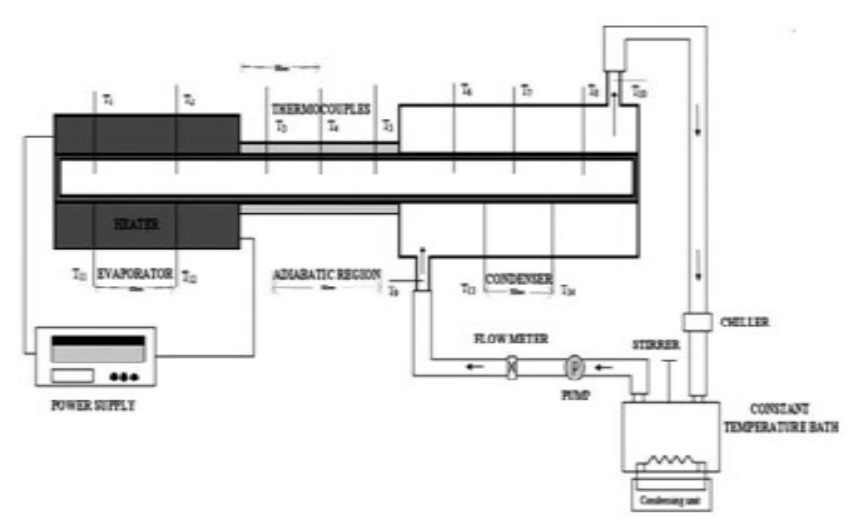

Fig 2. Schematic Diagram of Experimental Setup

\subsection{EXPERIMENTAL PROCEDURE}

To conduct the experiments and fill up the working fluid (Norflurane) in the system, the thermo-siphon is (degassed) evacuated using the vacuum pump to take away the dissolved gases. After evacuation, the thermo-siphon is completed with the necessary fill ratio for testing the particular parameter. Then the evaporator section is heated using the required power supply with the help of external heater. The power input varies from (0-350) watts and is maintained at a steady state for 45 minutes for each interval. Therefore when this procedure is being done, power input to the two phases blocked thermo-siphon is gradually raised to the desired power level. The surface temperatures at twelve distinguish locations along the evaporator section (three), adiabatic (two) and condenser section(five) and (inlet and outlet) of 2- phase closed thermo-siphon are measured at regular time intervals until the two phase blocked thermo- 
siphon with the help of T-Type Thermocouples. Once the steady state is reached, the input power is put off and cooling water is allowed to flow through the condenser in order to cool the 2- phase closed thermo-siphon and to make it ready for further experimental purpose. Again, the power is increased to the next level and the two phase closed thermo-siphon is well tried for its performance. This experimental method is repeated for distinct fill ratios namely $40 \%, 50 \%, 60 \%, 70 \%$ and $80 \%$ and for different inclinations of thermo-siphon namely $0^{\circ}, 45^{\circ}$ and $90^{\circ}$. These procedures were carried out by many research scholars themselves to find the optimum thermal performance [9] of the thermo-siphon. Similar investigations were carried out research scholar M. Yong Joo Park [10] et al wherein which the fill ratio was parameter used to judge the Thermal performance of the thermo-siphon. Various running fluids were used when similar procedures were carried out. Given below are some basic information of the components used and their respective descriptions.

N. P. Parate [11] et al also studied and analyzed their research under similar experimental procedure wherein which two phase closed thermo-siphon was analyzed with parameter such as fill ratio to derive the optimum thermal performance while employing it with several running fluid.

\subsection{ELECTRO CHEMICAL COATING}

Electro chemical coating is an organic coating technique, that uses electrical current to deposit paint onto a parts or a assemble products with specific performance. Because its capable to coat ever the most complex parts and assembled products.

The cleaning process is done before applying the electro chemical coating. The sodium-dichromate, sulphuric acid and the distilled water are used in clean the copper tube.

The combination of hydrogen sulphate $(0.6$ mole $)$ and copper sulphate $(0.8$ mole) are mixed with distilled water (1ltr). The solution used as electrolytic solution in electrochemical coating process. The coating can be applied only inner surface of the tube. The coating material (copper tube) is considered as cathode, the working material is considered as anode. The coating process done at of DC current.

\section{NOMENCLATURE}

$\mathrm{M}$

Cpi

I

Q1

Q2

$\mathrm{R}$

$\mathrm{Ti}$

To

Tv

Twc

Twe

V mass flow rate of water in condenser $(\mathrm{kg} / \mathrm{s})$ specific heat of water $\left(\mathrm{J} / \mathrm{kg}{ }^{\circ} \mathrm{C}\right)$

current (A)

inlet heat by evaporation (W)

outlet heat by condensation (W)

thermal resistance $\left({ }^{\circ} \mathrm{C} / \mathrm{W}\right)$

inlet water temperature of condenser $\left({ }^{\circ} \mathrm{C}\right)$

Outlet water temperature of condenser $\left({ }^{\circ} \mathrm{C}\right)$

Vapour temperature $\left({ }^{\circ} \mathrm{C}\right)$

Avg temperature of condenser section $\left({ }^{\circ} \mathrm{C}\right)$

Avg temperature of evaporator section $\left({ }^{\circ} \mathrm{C}\right)$

Voltage (v)

\subsection{CALCULATION OF THERMAL PERFORMANCE OF THERMO-SIPHON}

The Thermal resistance [12] of the Thermo-siphon is deliberated by using the following equation:

Where Twe, Twc are the average temperatures of the evaporate section and the condenser section and Q is the heat input granted varied across the experimental analysis.

The rate of heat transfer [12] at evaporator section is take out from the relation:

$\mathrm{Q}_{1}=\mathrm{I} \times \mathrm{V}$

The rate of heat removal [12] from the condenser section is computed from the following relation:

$\mathrm{Q}_{2}=\mathrm{m} \times \mathrm{Cpi}(\mathrm{T} 0-\mathrm{Ti})$

\section{OUTPUTS AND DISCUSSION}

\section{1 Effect of Filling Ratio on the Thermo-Siphon}

\section{Primary Analysis}

The effect of heat input on thermal resistance of two phase closed thermo-siphon at various fill ratio namely $(70 \%$ to $30 \%$ ) for Norflurane (Fig. 3 to 7 shows). It is clear from the figures that the thermal resistance of 2- phase blocked thermo-siphon deteriorates when the fill ratio decreases and heat input increases. This is a typical characteristic of the thermo-siphon in which dehydration takes place on the surface of a liquid pool in low down heat flux and nucleate boiling in a higher heat flux. Therefore thermal resistance reduces drastic with higher heat input [13]. At lower fill ratio of thermo-siphon and higher heat input, the thermal resistance is low thereby depicting the fact that there is a higher heat transfer. But in general when thermal resistance is lowered, heat transfer increases. But we see a slight increase in the thermal resistance after the deterioration from Fig 5 to 7 . Therefore a secondary analysis must be done for both fill ratios namely $60 \%, 50 \%$ and $40 \%$. This is done in order to find out the optimum fill ratio required for the enhanced thermal efficiency of the thermo-siphon.

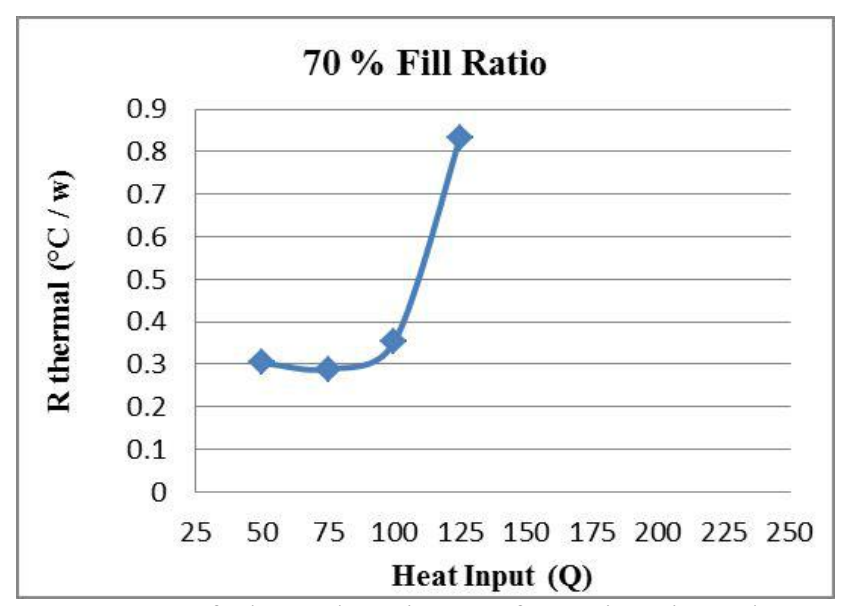

Fig 3. Curve of Thermal Resistance for various input heat at $70 \%$ Fill Ratio 


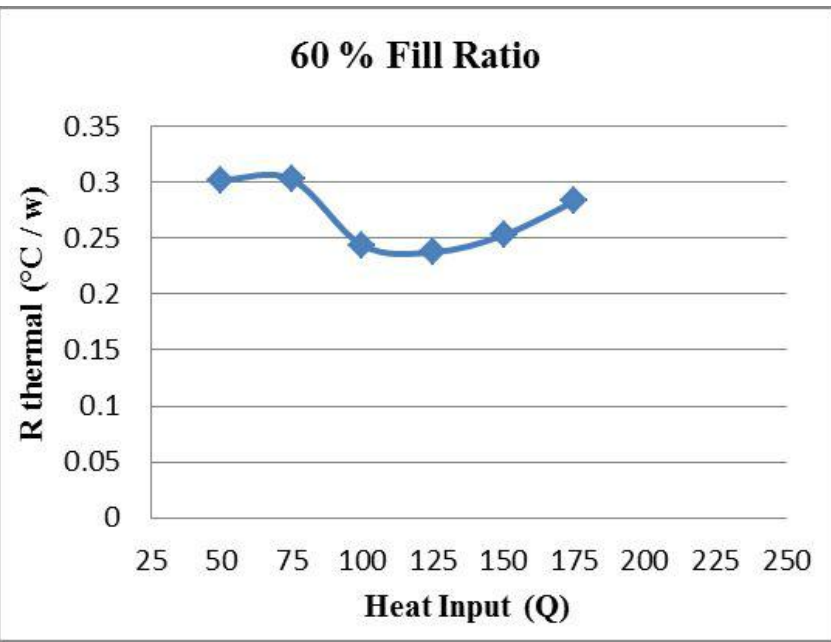

Fig 4. Curve of Thermal Resistance for various input heat at $60 \%$ Fill Ratio

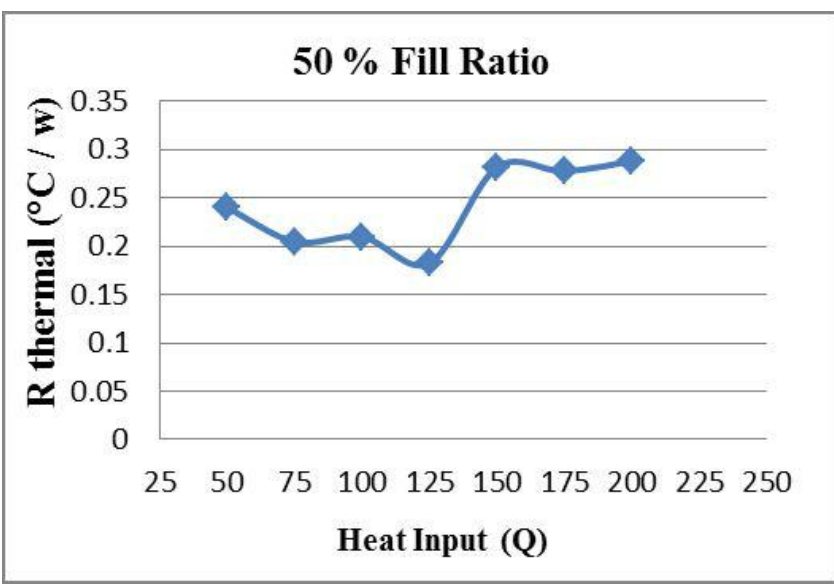

Fig 5. Curve of Thermal Resistance for various input heat at $50 \%$ Fill Ratio

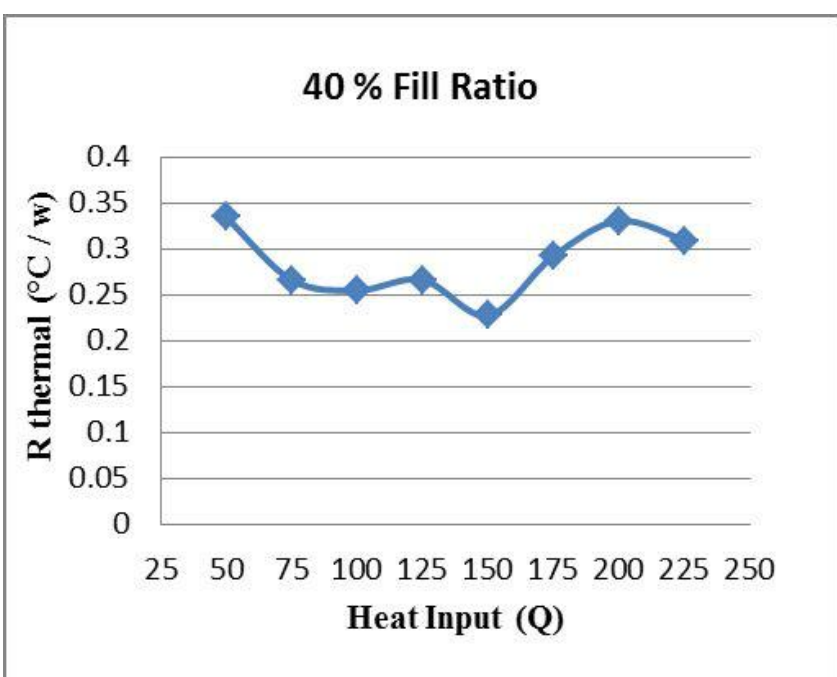

Fig 6. Curve of Thermal Resistance for various input heat at $70 \%$ Fill Ratio

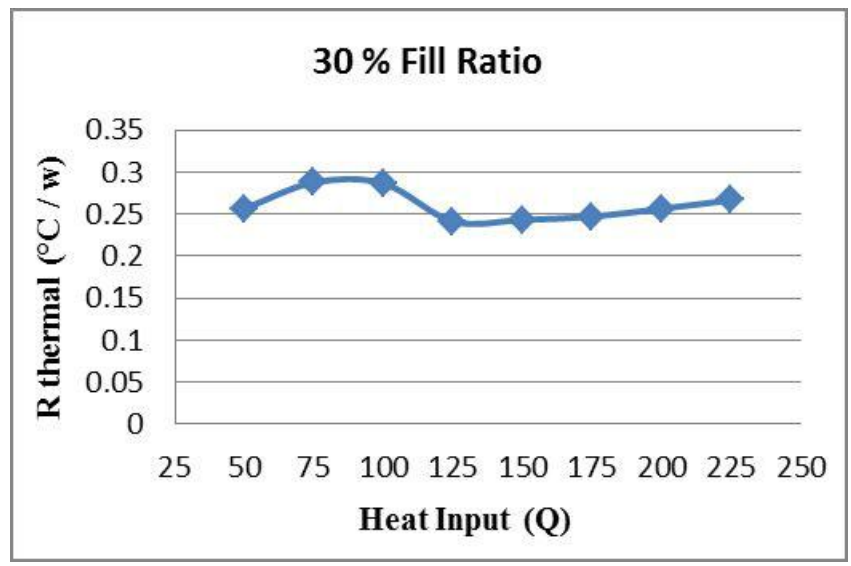

Fig 7. Curve of Thermal Resistance for various input heat at $30 \%$ Fill Ratio

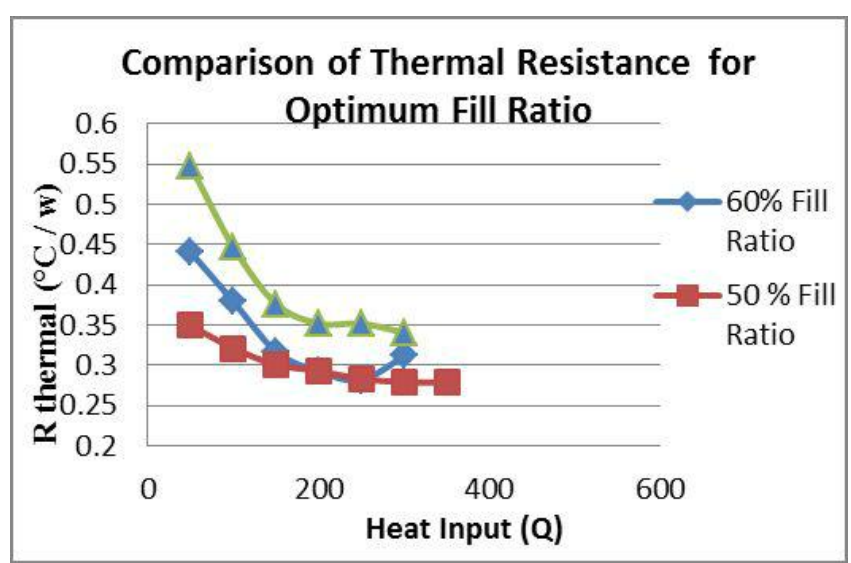

Fig 8. Curve of Thermal Resistance for various input heat at $(60 \%, 50 \%, 40 \%)$ Fill Ratios

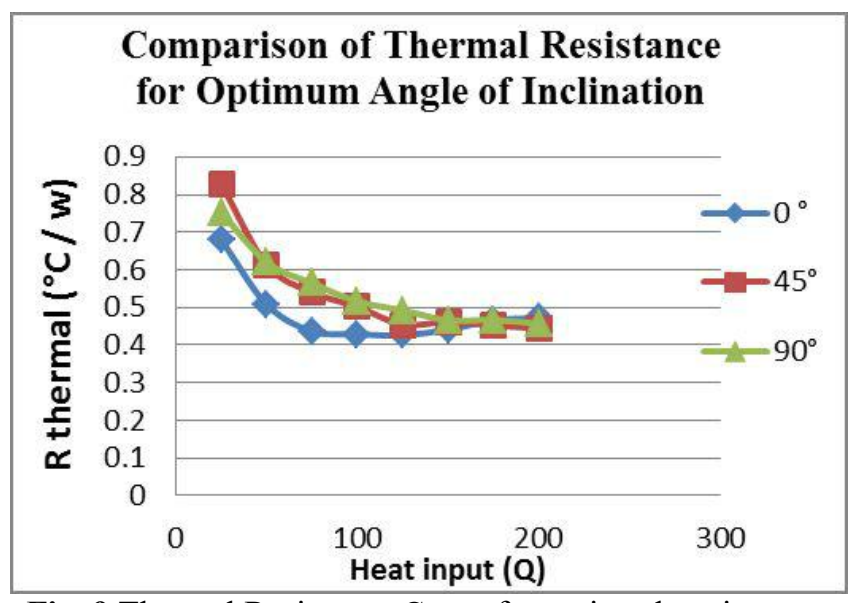

Fig. 9 Thermal Resistance Curve for various heat input at $(00,450,900)$ Angle of Inclination

\section{SECONDARY ANALYSIS}

From the above inference of the graph we find that at various heat the fill ratio of $50 \%$ gives the lowest of all thermal resistance. Therefore this shows that lower the thermal resistance, better the heat transfer transportability. This alone depicts that for the $50 \%$ fill ratio, thermo-siphon gives an efficient thermal performance. This can also be verified from various journals as far as thermo-siphons are concerned with various working fluid that $45 \%$ to $50 \%$ 
ratios are optimum. Therefore for further analysis like this optimum fill ratio can be proceeded to maintain optimum thermal performance.

\subsection{EFFECT OF ANGLE OF INCLINATION OF THERMO-SIPHON}

Fig.9 shown at various inclinations the Thermal resistance of heat pipe is filled on Norflurane. In the evaporate and condense sections the Thermal resistance of the thermosiphon is depicted by $(\mathrm{R})$ and TE and TC are average values of temperatures and $\mathrm{Q}$ is the heat furnished to the heat pipe. It is clear that the Thermal resistance of thermo-siphon cut down for increasing values of angle of disposition [14] and the heat input.

The thermal resistance of the thermo-siphon is high because of the comparatively solid liquid film that resides in the evaporator section at a low heat input. These thermal resistances distil quickly to their minimum value when the heat load increased [15]. Another important observation was the contact area of the horizontal surface.

\section{CONCLUSION}

The following observations were twofold:-

Firstly, the effect of fill ratio on the Thermal performance on 2- phase closed thermo-siphon charged with Norflurane was investigated. From $70 \%$ to $30 \%$ and at a power input of $25 \mathrm{~W}$ to $350 \mathrm{~W}$, the thermo-siphon was analyzed experimentally. With the limitations of flooding and dry out phenomenon occurring at $70 \%$ and $30 \%$ respectively it was deciphered from the analysis that $50 \%$ fill ratio was optimum for better thermal performance.

Secondly, the angle of inclination which projected more of heat transfer is $0^{\circ}$. This same fill ratio and angle of inclination will be carried out in further analysis of other parameters to fulfill the demand of thermal performance of the thermo-siphon.

It has wide scope of both electronic cooling and thermal management inside the aeronautical components; in due course its relations like thermal conductivity enhancement can be done with addition of same micro metals inside the tube through electroplating etc.

\section{ACKNOWLEDGEMENT}

The author would like to express their appreciation to the Karunya University Centre for research in thermal management, School of Mechanical sciences, Coimbatore, Tamilnadu-India for providing technical facility. This supports is gratefully acknowledged.

\section{REFERENCES}

[1].Amir Faghri, 2014 "Heat Pipes: Review,Opportunities and Challenges", Frontiersin Heat Pipes, ISSN: 2155-658X, (FHP), Vol. 5.1.
[2]. M. Kannan, 2014, “An Experimental Study on Heat Transport Capability of a Two Phase Thermo-siphon Charged with Different WorkingFluids", American Journal of Applied, (AJAS) , ISSN: 1546-9239, 584.591 Published Online, Sciences 11 (4): 584-591.

[3]. K. S. Ong , 2011, "Inclination and Fill Ratio, Effects on Water Filled Two-Phase Closed Thermo-siphon", International Heat Pipe Symposium, IHPS, Nov. 6-9, pp: 167.

[4]. Zuo, Z. J. , 1995 , "Heat transfer analysis of aninclined two-phase thermo-siphon". Journal of Heat Transfer, Vol. 117, pp. 1073-1075.

[5]. P.G. Anjankar, 2012 "Experimental Analysis of Condenser Length Effect on the Performance of Thermosiphon", InternationalJournal of Emerging Technology and Advanced Engineering, IJETAE, ISSN 2250-2459, Volume 2,Issue 3, PP: 494.

[6]. Alberto Cavallini, 1996 "Working fluids for Mechanical Refrigeration ", Int. J. Refrig, Published by Elsevier Science Ltd. Vol. 19, No. 8, pp. 485-496.

[7]. Ong, K. S., and Md Haider-E-Alahi, 2003 "Performance of a Norflurane-filled thermo-siphon. "Applied thermal engineering, Vol. 23.18 pp 2373-2381.

[8]. Grooten, M. H. M., and C. W. M. Van der Geld. , 2009 "Predicting heat transfer in long Norflurane filled thermo siphons."Journal of HeatTransfer, Vol.131.5: pp 051501.

[9]. M.G.Mousa, 2011 "Thermal Performance of Thermosiphon Charged by Nanofluid for Cooling Electronic Component", InternationalJournal of Scientific \& Engineering Research, IJSER, Vol. 2, Issue 6, June-2011, ISSN: 2229-5518.

[10]. Yong Joo Park, 2002, "Heat transfer characteristics of a two phase closed thermo-siphon to the fill charge ratio". International Journal of Heat and Mass Transfer. 45: 4655 $-4661$.

[11]. N. P. Parate ,H. S. Farkade, 2014, “Thermal Performance of a Two Phase Closed Thermo-siphon Using Nanofluid", InternationalJournal for Scientific Research \& Development,IJSRD, Vol. 2, Issue 04, ISSN : 2321-0613.

[12]. M. Karthikeyan, 2013 "Heat Transfer Analysis of Two phase Closed Thermo-siphon Using Aqueous Solution of N Butanol", International Journal of Engineering and Technology, Volume 3 No.6, June, IJET, ISSN: 2049-3444 .pp 661.

[13]. K. S. Ong and W. L. Tong, 2011 "Inclination and Fill Ratio Effects on Water Filled Two-Phase Closed Thermosiphon", International Heat Pipe Symposium, IHPS, Vol. 69, pp: 167

[14]. M. Karthikeyan, 2010, "Thermal Performance of A Two Phase Closed Thermo-siphon Using Aqueous Solution", International Journal of Engineering Science and Technology, Vol. 2(5), 913-918.

[15]. Senthilkumar R, 2012 "Effect Of InclinationAngle in Heat Pipe Performance Using Copper Nanofluid", Procedia Engineering, - Elsevier pp3715 - 3721. 